\title{
Inducible left ventricular obstruction after apical-conduit aortic valve bypass surgery
}

\author{
Catherine Y. Campbell, MD, ${ }^{\mathrm{a}}$ Ashish S. Shah, MD, ${ }^{\mathrm{b}}$ and Matthews Chacko, MD, ${ }^{\mathrm{a}}$ Baltimore, Md
}

Video clip is available online.

In recent years, apical-aortic bypass surgery has been used for patients with a heavily calcified or "porcelain" ascending aorta or hostile mediastinum because these patients would be at high risk for cerebrovascular events during crossclamping of the calcified ascending aorta. ${ }^{1-3}$ In this case, we describe a previously unreported complication of apical aortic bypass and illustrate the role of cardiac catheterization and ventriculography in the hemodynamic evaluation of this patient.

\section{CLINICAL SUMMARY}

A 69-year-old woman with an apical-aortic conduit placed 2 months before admission, hypertension, and endstage renal disease presented to the Johns Hopkins Hospital with disabling exertional chest pain and dyspnea, as well as severe hypotension noted during hemodialysis through a left-arm atrioventricular fistula. The apical-aortic conduit had been placed for severe calcific native aortic valve stenosis and a porcelain aorta (Figure 1). Preoperatively, she had an ejection fraction of $65 \%$ with severe concentric left ventricular (LV) hypertrophy and a valve area of $0.7 \mathrm{~cm}^{2}$ by echocardiography. She had no coronary artery disease by coronary angiography with a peak-to-peak transaortic valve gradient of $60 \mathrm{~mm} \mathrm{Hg}$ and valve area of $0.6 \mathrm{~cm}^{2}$ noted by cardiac catheterization.

Given the patient's dramatic and disabling postoperative symptoms, she was referred for repeat cardiac catheterization and hemodynamic assessment of her apical-aortic conduit. Coronary angiography showed no significant coronary artery disease beyond complete occlusion of the apical left anterior descending, presumably at the site of the apical

From the Divisions of Cardiology ${ }^{\mathrm{a}}$ and Cardiac Surgery, ${ }^{\mathrm{b}}$ The Johns Hopkins Hospital, Baltimore, Md.

Disclosures: None.

Received for publication March 5, 2010; accepted for publication May 14, 2010; available ahead of print July 12, 2010.

Address for reprints: Matthews Chacko, MD, Division of Cardiology, The Johns Hopkins Hospital, 600 N. Wolfe Street, Carnegie 568, Baltimore, MD 21287 (E-mail: mchacko1@jhmi.edu).

J Thorac Cardiovasc Surg 2010;140:e62-3

$0022-5223 / \$ 36.00$

Copyright (c) 2010 by The American Association for Thoracic Surgery

doi:10.1016/j.jtcvs.2010.05.027

conduit. Simultaneous pressures were measured in the LV, ascending aorta, and apical-aortic conduit, and pullback pressures were measured from the apical-aortic conduit to the descending aorta. A fixed $10 \mathrm{~mm} \mathrm{Hg}$ gradient was present across the anastomosis of the conduit to the descending aorta where a $20 \%$ to $30 \%$ stenosis was noted. Ventriculography at baseline showed a hyperdynamic LV cavity without obstruction and a surgically absent apex with an apicalaortic conduit in place. Intraventricular nitroprusside was administered to reproduce the afterload reduction experienced during hemodialysis through her arteriovenous fistula. After the administration of nitroprusside, the mid-LV cavity completely obliterated in systole associated with a marked increase in gradients from the LV to the conduit and from
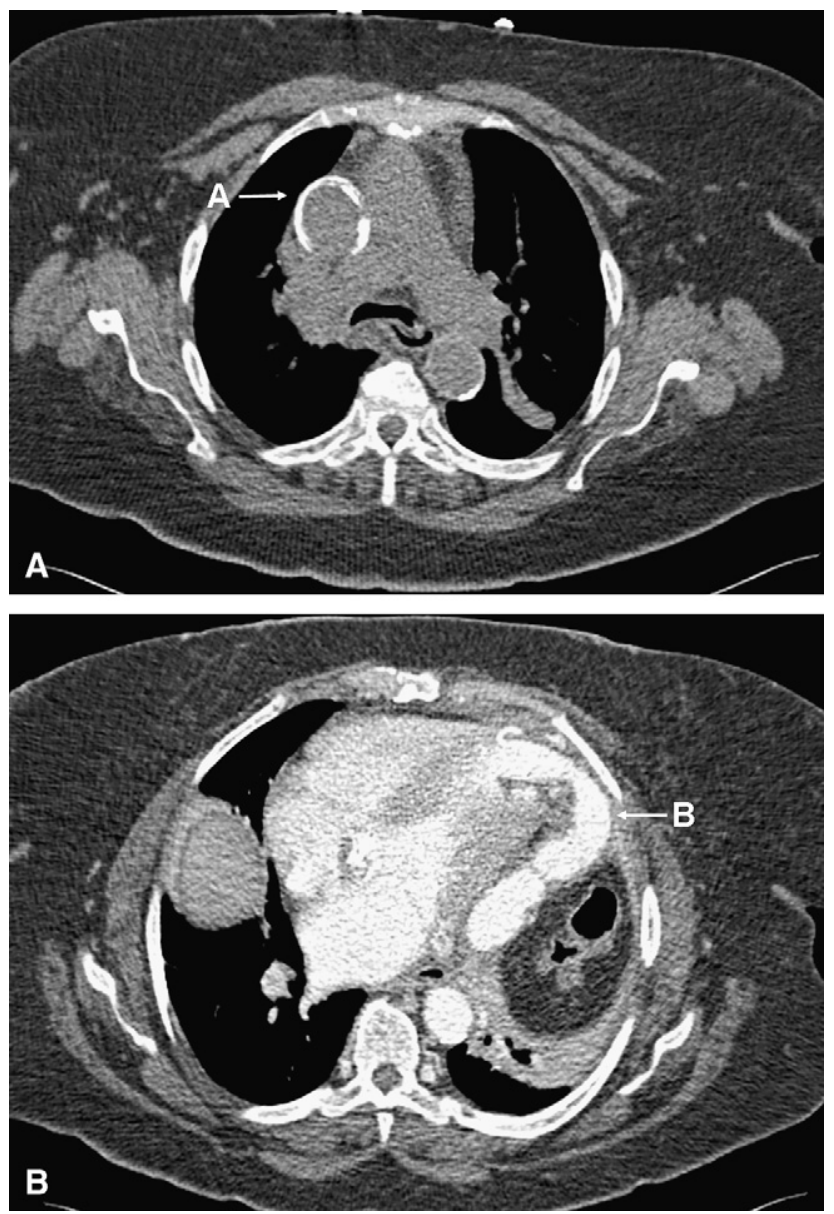

FIGURE 1. Computed tomography showing the porcelain ascending aorta (A) and the apical-aortic conduit (B). 


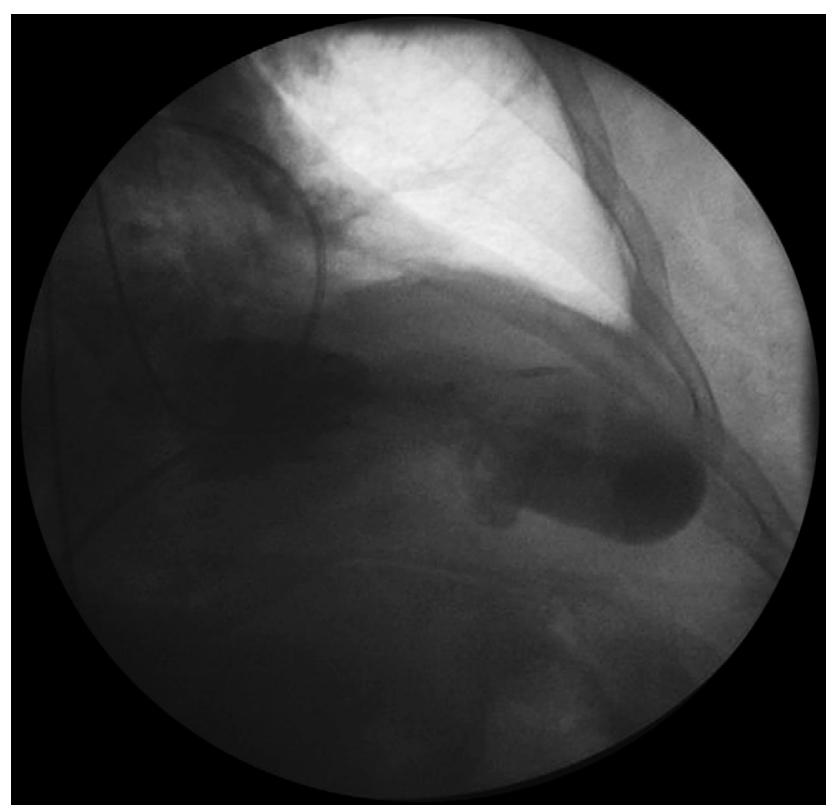

FIGURE 2. Left ventriculogram with nitroprusside (systole) and a straight flush catheter in the apical conduit. Note the complete obliteration of midLV cavity.

the LV to the aorta, hypotension, and a decrease in cardiac output (Figure 2).

\section{DISCUSSION}

The inducible mid-LV obstruction from a hyperkinetic ventricle functionally occluding the apical conduit was thought to be responsible for the hemodynamic changes noted and the likely cause of the hypotension experienced during hemodialysis through the patient's arteriovenous fistula. The patient was pretreated with midodrine for dialysis and eventually underwent conventional native aortic valve and ascending aorta replacement with a 21-mm Carpentier Edwards Magna bovine pericardial bioprosthetic valve
(Edwards Lifesciences, Irvine, Calif) and a 28-mm Hemashield graft. By using epiaortic ultrasound, a relatively disease-free area of the arch was directly cannulated. We considered axillary cannulation and antegrade selective cerebral perfusion; however, in our experience the period of circulatory arrest would be short and the patient had significant disease in her innominate artery that would preclude clamping. In addition, the patient's future dialysis access needs may require use of her axillary artery. The duration of circulatory arrest was 21 minutes, and total cardiopulmonary bypass time was 205 minutes. The patient's postoperative course was unremarkable. She experienced a marked improvement in dyspnea and now tolerates hemodialysis without hypotension.

\section{CONCLUSIONS}

We present a previously unreported complication of an apical-aortic conduit. ${ }^{2}$ This complex left heart physiology includes a combination of fixed and provokable obstruction to LV flow with fixed native aortic valve and distal conduit anastomotic stenoses working in parallel with a superimposed provokable mid-LV cavity obstruction and hypertrophic obstructive cardiomyopathy-like physiology. Patients with significant LV hypertrophy may be at increased risk for inflow obstruction. Cardiac catheterization with simultaneous recording of pressures in the LV, ascending aorta, and apical-aortic conduit can be used for hemodynamic assessment of an apical-aortic conduit and may be useful when $\mathrm{LV}$ obstruction is suspected.

\section{References}

1. Schmid C, Scheld HH, Tjan TD. Apicoaortic conduit-a technical modification Thorac Cardiovasc Surg. 2006;54:280-1.

2. Gammie JS, Krowsoski LS, Brown JM, Odonkor PN, Young CA, Santos MJ, et al. Aortic valve bypass surgery: midterm clinical outcomes in a high-risk aortic stenosis population. Circulation. 2008;118:1460-6.

3. Mills NL, Everson CT. Atherosclerosis of the ascending aorta and coronary artery bypass. Pathology, clinical correlates, and operative management. J Thorac Cardiovasc Surg. 1991;102:546-53. 